\title{
The history of KSSTA
}

\author{
Ejnar Eriksson
}

Published online: 10 November 2011

(c) Springer-Verlag 2011

When in 1980-1981, ESKA was formed on my initiative and with economic help from the city of West Berlin, we also contacted the Springer Company in Heidelberg, Germany, about publishing the Proceedings of the First Congress in Berlin in 1984. It was also decided that we would publish the proceedings as a book. Even for our 2nd ESKA Congress in Basle, Switzerland, ESKA published a book with the meeting proceedings. A problem that soon became evident was that the often excellent manuscripts from the meetings were not referenced by PubMed, since they were published in a book. The only way they would be cited in PubMed was to publish them in a scientific journal. This is one of the major reasons why ESKA decided to start a scientific journal. The board of ESKA therefore negotiated with a number of publishing houses. After some tough economical discussions, the Springer Company accepted the terms of ESKA and promised to publish the journal. The journal was named Knee Surgery, Sports Traumatology and Arthroscopy (KSSTA). The idea was to cover all aspects of sports traumatology, with major focus on knee injuries and knee surgery. As the journal has grown manuscripts on basic science, degenerative knee diseases and knee replacements have increased in number.

ESKA did not originally include sports traumatology in the name of the society. I was responsible for this delay of including sports trauma, since during the period 1980-1986, I was the president of the World Sports Medicine Federation (FIMS), and I wanted to avoid any collisions of interest between the new European society and FIMS. In 1988, however, ESKA included sports traumatology in its title and became ESSKA.

E. Eriksson $(\square)$

Lugnets Väg 11, 18634 Vallentuna, Sweden

e-mail: eriksson.werner@telia.com
KSSTA was originally published with four issues in 1993. I was the president of ESSKA and became the first Editor-in-Chief after I stepped down as ESSKA president. I held the position as Editor-in-Chief for 15 years, until 2008. My plan for KSSTA was to try to keep such a high scientific standard that a high impact factor would be possible.

The first years of KSSTA were tough. The journal did not receive enough good manuscripts to fill the issues. Many ESSKA members were used to submit their scientific papers to American or British journals, and since we did not yet have an impact factor, it was difficult to compete with the established journals. After 3 years, the journal received its first impact factor and it was surprisingly good. This increased our members' interest of publishing in KSSTA. While the journal was originally published as four relatively thin issues in 1993, it increased the number of issues gradually first to 6 , then 8 , and finally 12 issues per year. The issues also became thicker and thicker-often more than 100 pages. It meant a lot of work, especially for my secretary Louise von Essen, who was responsible for all administration of the journal during 16 years. She did all this work after hours and in weekends.

One of the biggest problems for me in the beginning of KSSTA's history was to find good reviewers who returned the manuscripts in time. I guess that this is a similar problem for my successors. It takes a lot of work to make a good review of a scientific paper and it takes time. The only "payment" the reviewers get is to be mentioned in the last issue of KSSTA each year. In the future, we need to find a better system for rewarding this important scientific work.

I wish KSSTA a glorious future, and I am happy to have played a role when it was created. 